\title{
Bacterial Microcompartments
}

Cheryl A. Kerfeld, ${ }^{1,2}$ Sabine Heinhorst ${ }^{3}$ Gordon C. Cannon ${ }^{3}$

${ }^{1}$ US Department of Energy - Joint Genome Institute, Walnut Creek, CA 94598

${ }^{2}$ Department of Plant and Microbial Biology, University of California, Berkeley, CA 94720 USA

${ }^{3}$ Department of Chemistry and Biochemistry, The University of Southern Mississippi, Hattiesburg, MS 39406 USA

Contact Info:

ckerfeld@lbl.gov

sabine.heinhorst@usm.edu

gordon.cannon@usm.edu

Running Title: Bacterial Microcompartments

Corresponding author: Cheryl Kerfeld

Ckerfeld@lbl.gov

Ph: (925) 296-5691

Key words: bacterial microcompartment, carboxysome, horizontal gene transfer, bacterial organelle, polyhedral bacterial inclusions 
CONTENTS

INTRODUCTION

FUNCTIONAL PARADIGMS FOR BMCs

Carboxysomes

Pdu BMCs

Eut BMCs

Models for Pdu BMC and Eut BMC Function

STRUCTURAL STUDIES ON PROTEINS OF THE BMC SHELL

Single BMC-domain containing Proteins

Tandem BMC-domain containing Proteins

Closing the BMC Shell: Pf03319 Proteins and Assembly of BMCs

BMC DIVERSITY, HORIZONTAL GENE TRANSFER AND EVOLUTION 


\begin{abstract}
Bacterial microcompartments (BMCs) are organelles composed entirely of protein; they promote specific metabolic processes by encapsulating and co-localizing enzymes with their substrates and cofactors, protecting vulnerable enzymes in a defined microenvironment and by sequestering toxic or volatile intermediates. Prototypes of the BMCs are the carboxysomes of autotrophic bacteria. However, structures of similar polyhedral shape are being discovered in an ever increasing number of heterotrophic bacteria, where they participate in the utilization of specialty carbon and energy sources. Comparative genomics reveals that the potential for this type of compartmentalization is widespread among bacteria phyla and suggests that genetic modules encoding BMCs are frequently laterally transferred among bacteria. The diverse functions of these BMCs suggest that they contribute to metabolic innovation in bacteria in a broad range of environments.
\end{abstract}

\title{
INTRODUCTION
}

It is increasingly evident that the interior of the bacterial cell is highly organized (29). One of the emerging paradigms for organization within the prokaryotic cell is the bacterial microcompartment (BMC; Figure 1), an organelle composed entirely of protein. BMCs encapsulate functionally related enzymes and auxiliary proteins within a thin protein shell. Concentrating enzymes together enhances catalytic efficiency by enabling the direct transfer of intermediates between enzymes that catalyze sequential reactions. The shell also provides a barrier to loss of metabolites to diffusion and competing pathways; similarly, by sequestering toxic intermediates it prevents their interference with the bulk of cellular metabolism. 
BMCs were discovered through electron microscopy. A striking feature of the BMC is its profile in electron micrographs (Figure 1), suggestive of a polyhedral morphology and implying an unusual level of geometric organization. After they were first described in 1956 (23), some investigators assumed they were phages (8). Since then, BMCs have been called polyhedral bodies, polygonal bodies, carboxysomes, enterosomes and metabolosomes, reflecting the growing understanding of their diverse functions. This review describes our current understanding of BMC function and structure, beginning with the genetic and biochemical studies on the most extensively characterized BMC, the carboxysome, and the two relatively well-characterized BMCs of enteric bacteria that are involved in ethanolamine (Eut BMC) and propanediol utilization (Pdu BMC). These have become the focus of X-ray crystallographic studies which have led to an understanding of the structural basis of BMC function. The structural studies have also helped clarify what defines a BMC: two types of shell protein. This, coupled with comparative genomics, has led to our ability to detect the widespread occurrence of BMCs among diverse bacteria, implicating them as frequently laterally transferred metabolic modules that are important for environmental adaptation.

\section{FUNCTIONAL PARADIGMS FOR BMCs}

\section{Carboxysomes}

The first to isolate BMCs, from the chemoautotrophic bacterium Halothiobacillus neapolitanus, Shively and colleagues demonstrated that they contain the central enzyme of the Calvin-BensenBassham cycle, ribulose-1,5-bisphosphate carboxylase/oxygenase (RubisCO), and named them carboxysomes (61) (Figure 2a). Two opposing hypotheses about their biological function centered on the notions that either carboxysomes serve as a storage compartment for inactive 
RubisCO, or the rather poor kinetic properties of RubisCO are enhanced by packaging the enzyme inside the BMC. It is now well established that carboxysomes are, indeed, active in $\mathrm{CO}_{2}$ fixation. This conclusion was reached after studies demonstrated that the isolated particles contain highly active RubisCO (reviewed in(13)). In addition, all carboxysomal RubisCO in permeabilized $H$. neapolitanus cells was shown to be in its fully activated state by in situ experiments (14). Physiological evidence supporting an active role of the carboxysome in $\mathrm{CO}_{2}$ fixation includes the observation in both chemolithotrophic bacteria and cyanobacteria that the number of carboxysomes and the expression of carboxysome genes increase significantly when cells are limited for $\mathrm{CO}_{2}$ (reviewed in (32)). Some mutants, selected from a population of chemically mutagenized cyanobacteria that display a high $\mathrm{CO}_{2}$ requiring (her) phenotype, lack or form aberrantly shaped carboxysomes, suggesting that functional carboxysomes are needed for efficient growth at ambient $\mathrm{CO}_{2}$ levels (48-50). After the carboxysome operon (cso operon) was identified, targeted mutagenesis of individual genes could be correlated with changes in carboxysome appearance or their disappearance, and the hor phenotype $(6,12,22,24,42)$.

Most autotrophic bacteria live in environments in which dissolved inorganic carbon (DIC) concentrations are well below those needed to support RubisCO-mediated $\mathrm{CO}_{2}$ fixation. The carboxysome actively enhances $\mathrm{CO}_{2}$ fixation by increasing the steady-state concentration of $\mathrm{CO}_{2}$ in the vicinity of the active site of RubisCO, thereby overcoming the poor affinity of the enzyme for its substrate and allowing it to operate at or near substrate saturation $(3-5,20,35,51,52)$. Dissolved inorganic carbon is actively accumulated in the cell. The cytoplasmic DIC, which consists largely of bicarbonate, enters the carboxysome, presumably by diffusion, and is rapidly equilibrated with $\mathrm{CO}_{2}$ by a specialized carbonic anhydrase that is co-localized with RubisCO within the carboxysome (recently reviewed in (16)). The shell of the carboxysome limits the 
escape of $\mathrm{CO}_{2}$ out of the BMC and into the cytoplasm (Figure 2a). Quantitative models of $\mathrm{CO}_{2}$ assimilation and growth of cyanobacteria $(1,54-56)$, as well as ample experimental data in chemoautotrophs and cyanobacteria strongly support this mechanism of carboxysome function.

Carboxysomes have been categorized into two types based on the RubisCO ortholog they contain and their shell protein composition. Carboxysomes of the $\alpha$-type are found in chemoautotrophs and in some marine cyanobacteria. They are encoded by cso operons of very similar organization. By contrast, $\beta$-carboxysomes, which are found mainly in freshwater cyanobacteria are encoded by ccm genes that are distributed throughout the genome $(2,15)$. As discussed below, two shell protein types are homologous in $\alpha$ - and $\beta$-carboxysomes (15). However, although morphologically similar, many $\beta$-carboxysomes are larger and tend to be less regularly shaped than $\alpha$-carboxysomes, which could imply some functional variation. One suggestion that has persisted in the literature is that the carboxysomal shell protects RubisCO from $\mathrm{O}_{2}$, the competitive inhibitor of the enzyme. The necessity for such a role is difficult to justify in the chemoautotrophs, in which $\mathrm{O}_{2}$ concentrations are not likely to be very high relative to intracellular DIC concentrations. The oxygenic photosynthesis activity of cyanobacteria, on the other hand, may very well necessitate that their carboxysomes exclude oxygen from RubisCO in their interior.

\section{Pdu BMCs}

Degradation of the common plant cell wall sugars fucose and rhamnose under anaerobic conditions produces 1,2-propanediol, which is used as a carbon and energy source by a number of enteric bacteria and by those that grow in environments such as aquatic sediments, where 1,2- 
propanediol is readily available due to the breakdown of plant material. Catabolism of 1,2propanediol requires a complex pathway that is coenzyme B12-dependent and ultimately provides the cell with propionyl-CoA, an electron sink, and ATP (Figure $2 \boldsymbol{b}$ ). The proteins that are involved in 1,2-propanediol degradation are encoded by the 23 genes of the 1,2-propanediol utilization ( $p d u$ ) operon (34). It was surprising to find that seven of these genes are homologous to carboxysome shell protein genes (17). Subsequent electron microscopic studies showed that, when grown on 1,2-propanediol, Salmonella enterica Serovar Typhimurium LT2, Klebsiella oxytoca (62), and Lactobacillus reuteri DSM 20016 (63) contain multiple polyhedral bodies that resemble carboxysomes in size, shape and electron density (Figure 1b). Immunogold labeling of cell thin sections demonstrated that diol dehydratase (PduCDE) and propionaldehyde dehydrogenase (PduP) are components of the Pdu BMC core (Figure 2b) (7, 40). An inventory of polypeptide constituents of the Pdu BMC established by two-dimensional gel electrophoresis/mass spectrometry analysis of particles isolated from S. enterica suggested that additional proteins involved in the Pdu pathway are associated with the BMC (30).

\section{Eut BMCs}

Ethanolamine is produced in the gastrointestinal tract of mammals as a result of the degradation of the membrane component phosphatidyl ethanolamine. This amino alcohol is an important source of carbon, nitrogen and energy for many bacteria that inhabit the mammalian gut (65). As in the $p d u$ operon, genes for enzymes that catalyze reactions in the ethanolamine degradation pathway are clustered in the eut operon with genes encoding homologs of carboxysome shell proteins (65). The presence of polyhedral inclusions in thin-sectioned S. enterica cells grown on ethanolamine was shown by transmission electron microscopy (TEM) $(10,38)$, but to date, a 
purification procedure for Eut BMCs has not been reported, and their exact composition is therefore unknown. However, since the chemistry of the Eut pathway parallels that of the Pdu pathway to some extent, it has been proposed that ethanolamine enters the BMC through the shell and is converted to acetaldehyde and ammonia by coenzyme B12-dependent ethanolamine ammonia lyase (EutBC (25)) in the interior (Figure 2c); co-localized EutA protein ensures that the enzyme remains in an active state $(44,60)$.

\section{Models for Pdu BMC and Eut BMC Function}

Although the exact roles of the Pdu and Eut BMCs in the metabolism of 1,2-propanediol and ethanolamine, respectively, have yet to be elucidated, three models have been put forth for the biological function of these BMCs. The first model, and the one that is supported by the largest body of experimental evidence for the Pdu BMC, suggests that the BMC shell acts as a diffusional barrier to propionaldehyde and prevents leakage of this intermediate into the cytoplasm, where its relatively high reactivity could have deleterious effects on other cellular components $(7,57)$. The analogous function of the EutBMCs would be to contain acetaldehyde until it is further metabolized to acetyl-CoA by acetaldehyde dehydrogenase (EutE (65)) in the $\mathrm{BMC}$ interior prior to entry into the central metabolism, or converted to acetyl-phosphate by a phosphotransacetylase (EutD $(9,64))(10)$ (Figure 2c). An alternate branch of the pathway, presumed to be contained within the BMC as well, would convert acetaldehyde to ethanol through action of the putative alcohol dehydrogenase EutG $(10,64)$ (Figure 2c).

Since there does not seem to be an absolute requirement that ethanolamine be metabolized in BMCs in S. enterica (10), the second model for the primary role of the Eut BMC in ethanolamine metabolism proposes that BMCs increase the local concentration of key enzymes, 
their substrates and cofactors, and thereby ensure optimum metabolic efficiency (10). The advantages of compartmentalizing entire pathways or parts thereof are obvious, and this model would be applicable to all BMC types. However, the Pdu and Eut BMCs are clearly more complex at the molecular level than carboxysomes; they contain several linked key metabolic enzymes, additional proteins that maintain enzyme activity and possibly those that provide the necessary coenzyme. Aside from ensuring the proper internal concentration of coenzyme B12, the levels of $\mathrm{NAD}^{+} / \mathrm{NADH}$ inside those BMC must also be maintained. This may involve some as yet unknown cycling or transport mechanism across the BMC shell. Although the available evidence supports a role of these BMCs as very sophisticated machines for metabolite channeling, to date little work has been published regarding the kinetic parameters of the enzymes they contain. Since Pdu BMCs can be purified (30), detailed studies of individual enzyme activities and of the entire Pdu pathway in intact and disrupted BMCs should be possible and would provide the much needed direct evidence that can help assign definitive function(s) to the particles.

The third model for BMC function is based on the premise of a unified function for all BMCs. In analogy to the documented role of carboxysomes in concentrating $\mathrm{CO}_{2}$, Penrod and Roth (47) proposed that the main function of Eut and Pdu BMCs is to concentrate a valuable, yet volatile metabolite by containment within the BMC, which provides a special environment. The authors characterized the phenotypes of a battery of mutants that carry deletions in individual eut genes. Those lacking the genes needed for BMC formation or for downstream acetaldehyde metabolism (eutG or eutE) release more acetaldehyde than the wild type, similar to what was observed with a mutant unable to form Pdu BMCs (31). However, contrary to the growth arrest of the pduA mutant in the presence of 1,2-propanediol, growth of these eut mutants on ethanolamine is not 
impaired, suggesting that accumulation of acetaldehyde at this level is not toxic to S. enterica. The inability of the mutants that lack Eut BMCs to grow on ethanolamine under conditions that increase loss of acetaldehyde from the cells (high $\mathrm{pH}$ and increased gas exchange) suggested that perhaps the inside of the Eut $\mathrm{BMC}$ is maintained at a lower $\mathrm{pH}$ than the cytoplasm and effectively traps the acetaldehyde. A role of BMCs as a low-pH "cage" would also explain how carboxysomes enhance the catalytic efficiency of RubisCO by providing an interior environment with an increased concentration of $\mathrm{CO}_{2}$. The proposed mechanistic commonality for all BMCs is intriguing in light of the shared architectural principles of their shells (see below). However, the multiple reactions and complex milieus required by different enzymes, metabolites and cofactors within the three BMC are likely to sustain more than one function and different, well regulated flux mechanisms across the respective BMC shells. As pointed out by Penrod and Roth (47), there are serious mechanistic problems with the assumption that a protein shell can supplant the functions of a lipid bilayer-based membrane, as proposed by current models of BMC function. However, recent advances in the structural analysis of shell proteins from all three BMC types has demonstrated a rich assortment of possible paths across the compartment shells, with the potential for regulation of metabolite transfer by gating $(37,69)$.

\section{STRUCTURAL STUDIES ON PROTEINS OF THE BMC SHELL}

\section{Single BMC-Domain Containing Proteins}

The defining feature of a BMC is the proteinaceous shell. The shell confines the constituent enzymes and other proteins and likely plays a role in their organization. Like the lipid bilayers that bound other organelles, the structure of the shell establishes a permeability barrier. 
However, the selectivity properties of this proteinaceous barrier are opposite relative to those of biological membranes, with a preference for free passage of polar instead of nonpolar molecules.

The $\sim 80$ residue sequence that was recognized as the common denominator among the carboxysome, Eut and Pdu microcompartments has become known as the bacterial microcompartment domain (Pf00936). Genes encoding these domains consistently occur in multiple copies in BMC gene clusters. Building a macromolecular assembly from several small, essentially identical proteins requires less genetic material than constructing it from a single protein chain, a strategy is seen in viral capsids, flagella and the cytoskeleton.

Because of the intrinsic relationship between structure and function in proteins involved in subcellular architecture, structural studies of the BMC-domain containing proteins have been profoundly insightful. In 2005 Kerfeld et al. (36) described the first crystal structures of CcmK2 and CcmK4, two of the paralogs that form the $\beta$-carboxysome shell. The BMC domain adopts an $\alpha / \beta$ fold; six copies self assemble into cyclic hexamers, $\sim 70 \AA$ in diameter (Figure 3). Residues distinctive of specific CcmK paralogs converge at the six-fold axis of symmetry; because these are positively charged sidechains the electrostatic potential of the pore is strongly positive, likely providing an electrostatic attraction to the negatively charged metabolites that must cross the carboxysome shell. The diameter of the pore is relatively restrictive, $4 \AA$ and $7 \AA$ in $\mathrm{CcmK} 4$ and $\mathrm{CcmK} 2$, respectively. Compared to pores in transmembrane proteins, the pores in BMC proteins are shorter and less contoured, suggesting that they are relatively unselective (70). Presumably flux across the shell is driven by the magnitude and the direction of the concentration gradient of the metabolites. For example, in the carboxysome (Figure 2a), relatively high cytosolic concentrations of bicarbonate would support diffusion into the carboxysome, where the carbonic anhydrase would quickly convert it into $\mathrm{CO}_{2}$, thereby 
maintaining the concentration gradient of bicarbonate across the shell. Moreover, the arrangement of the CcmK2 hexamers in the crystal provided further insight into the architecture of the carboxysome shell; the hexamers are arranged as uniformly oriented layers (Figure 3) that were immediately suggestive of how the facets of the carboxysome shell are constructed (36). These interpretations were supported by similar observations in the structural analysis of CsoS1A from the $\alpha$-carboxysome (70).

The first structure of a shell protein from the Pdu BMC, the minor component PduU (18), confirmed the role of the BMC domain as a hexameric building block of the shell, however it also added variation to the theme (Figure 3). In PduU a $\beta$-barrel is formed by residues $8-15$ of each of the subunits in the hexamer; this caps the pore on one side, presumably precluding metabolite flow. Recently, another variation was described for the PduU homolog EutS (69). The EutS hexamer is twisted about the axis defined by the central $\beta$-barrel; the effect is to introduce a bend of $\sim 40^{\circ}$ to the hexamer (Figure 3). This is approximately the angle between adjoining faces in an icosahedron, suggesting that the edges where two facets of the BMC shell meet could be comprised of hexamers of this morphology. However, the lack of a phenotype for a $\triangle$ eutS mutant in Salmonella led to the suggestion that EutS plays only a subtle role in Eut BMC function (47), whereas its presumed structural role would seem to be critical.

\section{Tandem BMC-Domain Containing Proteins}

A comparison of the various BMC gene clusters in bacterial genomes (discussed below) shows that many contain genes that encode tandem BMC proteins of $\sim 180-250$ amino acids. The first structure of a tandem BMC protein, the carboxysomal protein CsoS1D, was reported in 2009 (37), revealing that tandem BMC proteins form trimers that structurally mimic the hexamers 
formed by single BMC domain proteins (Figure 3). The structure of CsoS1D also provides a possible solution to a paradox about transport across the BMC shell. Given the small diameter of the pores observed in the BMC shell protein hexamers up to that time, it was unclear how larger metabolites (e.g. RubP, 3-PGA) cross the shell. The structure of CsoS1D revealed that shell proteins could be gated; an absolutely conserved Arg sidechain converging at the three-fold axis of this pseudohexamer appeared in two distinct conformations; one in which the three Arg sidechains converge to obstruct the pore and a second in which the sidechains extend away from surface of the protein, leaving an opening $14 \AA$ in diameter (Figure 3).

A second observation for a putative two-state pore in a tandem BMC protein was described for EutL $(58,68)$, in which the open form has a negatively charged pore of $11 \AA$ in diameter, and the relatively closed form has three small perforations (of $2.2 \AA$ diameter at their narrowest point), each formed within a subunit (Figure 3). An additional observation of pores formed within a tandem BMC protein, similar to those in the relatively closed form of EutL, was reported for the newly described Etu BMC (33). These perforations (less than $\sim 3.8 \AA$ in diameter) are strongly negatively charged and lined by the sidechains of conserved residues. Heldt et al. concluded that they are competent for passage of ethanol, which must cross the Etu BMC shell (33). The small diameter and the relative asymmetry of these openings may increase their selectivity. Moreover, as the authors of the reports of the first EutL (58) and the EtuB structure (33) point out, having three pores per unit area in the BMC shell, as opposed to one, has significant implications for increased flux across the shell.

\section{Closing the BMC Shell: Pf03319 Proteins and Assembly of BMCs}


The numerous similarities between the emerging picture of the underlying architecture of the carboxysome and viral capsids suggested that there may be a protein that forms pentamers; the consistent presence of an ORF encoding the Pf03319 domain in the carboxysome, Pdu and Eut gene clusters made it a likely candidate. In 2008 Kerfeld, Yeates and their team undertook structural studies of the Pf03319 proteins from the two types of carboxysome, revealing that this domain indeed forms pentamers (67) (Figure 3). This also confirmed that the proteins composing the shell could be arranged with icosahedral symmetry. However, there are several observations that have yet to be reconciled with this model; deletion of the Pf03319 domain proteins in the $\alpha$-carboxysome gene cluster does not appear to affect carboxysome morphology (12). Moreover, two independent structural analyses showed that the single Pf03319 protein of the eut operon forms hexamers $(27,67)$.

There are other observations that remain to incorporated to develop a complete picture of the BMC architecture and function. For example, CsoS1D trimers dimerize to form tightly appressed hexamers (37); are these structures incorporated into a monolayer shell or do they reflect the physical interaction between two carboxysomes that is sometimes observed in TEMs. Similar, but less tightly associated dimers of hexamers have been observed for other BMC shell proteins $(18,36,68)$. The roles of specific side chains and their conformations underlying the interaction between hexamers in a monolayer have been pointed out $(37,68)$ but there are numerous principles governing BMC assembly that await elucidation. The role of the variations at the $\mathrm{N}$ and C-termini of the shell proteins also will likely prove to be important. As pointed out in the first structural description of the BMC domain (36), the disposition of the C-terminal helix appears to be important for the interactions between hexamers and/or may be important for interaction with encapsulated enzymes. Moreover, structural evidence supports the importance 
of the N-terminus in structural plasticity of shell proteins; the PduU structure revealed that its primary structure contains a permutation relative to the canonical BMC domain. The $\beta$-barrel formed by this segment of the hexamer is apparently functionally important for EutS and PduU $(18,69)$. In EtuB (33) and CsoS1D (37), the N-terminal 50-70 amino acids could not be structurally resolved, thus their potential role in the structure of the BMC is unknown.

\section{BMC DIVERSITY, HORIZONTAL GENE TRANSFER AND EVOLUTION}

Until relatively recently, the diversity and abundance of BMCs among the bacteria was underappreciated, given that detection was dependent on TEM of thin sections of cells that were serendipitously grown under conditions inducing expression of BMC gene clusters. Now, using the sequences of the BMC shell proteins as probes, comparative genomics approaches provide a new detection method for the potential to form BMCs. As of December 2009, open reading frames encoding BMC-domain containing proteins have been found in over 400 of the 1962 microbial genomes for which data are available. These are distributed broadly across bacterial phyla (Table 1). There are many cases in which there are two or three functionally distinct BMC gene clusters within the same organism. Examination of the ever-increasing number of gene clusters detected in genome sequence data permits some generalizations to be made about the requisite building blocks of all BMCs. In terms of their shell protein complement, there appears to be a requirement for two or more BMC domain proteins to be present in addition to 1-2 and sometimes three copies of the Pf03319 domain. In the few cases that violate these rules (Lactobacillus hilgardi and four Shigella species), the remaining BMC gene cluster appears to be defunct, containing pseudogenes and/or transposases. 
By examining the other ORFs in proximity to those encoding shell proteins, inferences can be made about the function of the BMC; often it appears to be encapsulation of an oxygen sensitive enzyme and/or because an enzymatic step involves a toxic or volatile intermediate. The most common of the bioinformatically identified BMCs are those containing a B12-independent glycerol dehydratase (Table 1). These enzymes are structurally distinct from the B12-dependent diol dehydratase encapsulated in the Pdu BMC (53). Instead, they resemble pyruvate formate lyase (45) and use an oxygen-sensitive glycyl radical mechanism involving S-

adenosylmethionine as a cofactor. Differences in the residues of the putative active sites in these homologs suggest that they may bind a range of substrates. A recent study combining bioinformatic-driven hypotheses tested by genome-wide microarray studies, TEM and product analyses (Figure 1e) has led to the demonstration that a BMC cluster containing a B12independent diol dehydratase in Clostridium phytofermans is involved in the fermentation of the plant cell wall components fucose and rhamnose into propanol (J Blanchard, pers comm.). This $\mathrm{BMC}$ cluster is one of three in the C. phytofermans genome; it is in addition to a eut operon and a second gene cluster containing another homolog of the B12 independent diol dehydratase with an unknown substrate preference.

Additional challenges for inferring BMC function occur in cases in which the BMC appears to be encoded by more than one locus within the genome, as is the case for the $\beta$-carboxysome. The Etu BMC of Clostridium kluveryi (Figure 2d), the subject of the structural analysis (33) noted above, is another example. C. kluveryi has long been known to form BMCs; in 1979 (41) ultrastructural evidence was published demonstrating the presence of BMCs when the organism is grown on ethanol and acetate (Figure 1d). The genome sequence, reported in 2008 (59), revealed a candidate BMC locus encoding the enzymes needed to oxidize ethanol to acetyl-CoA: 
it contains two shell proteins, EtuA and EtuB (discussed above), two acetaldehyde dehydrogenase paralogs and three alcohol dehydrogenase paralogs. Given the paucity of ORFs encoding shell proteins in this locus, especially the absence of a Pf03319 ortholog in this gene cluster, it was proposed that other constituent shell proteins of the Etu BMC are encoded by a defunct glycerol dehydratase BMC gene cluster apparent in the genome (33).

Numerous other types of BMC gene clusters can be identified based on the co-occurrence of the Pf00936 and Pf03319 domains in microbial genomes. In some cases functions can be suggested on the basis of annotation, but as such, they are tenuous (Table 1). Some of the less well sampled lineages in terms of genome sequencing contain organisms that have multiple clusters of shell proteins scattered in the genome; these include Solibacter usitatus, Haliangeum ochraceum and Chloroherpeton thalassium. This may reflect that operon-based architecture is less common among many bacteria than is generally assumed (26); accordingly, genome context predicts only a relatively small number of functional interactions among proteins (11). Considering this, widespread distribution of intact BMC-encoding modules in bacterial genomes is remarkable. The same type of BMC can be found across phyla (Table 1), while closely related organisms can differ in the number of BMC gene clusters. Collectively, the distribution of BMC gene clusters among the bacteria suggests that they are frequently laterally transferred and supports the concept of the selfish operon (39). That is, the lateral transfer of a unit of function encoded by several physically proximal genes is more likely to be retained because it is more likely than a single gene to be adaptive immediately upon introgression. Moreover, if newly introgressed BMC modules are functionally integrated with the products of genes and gene clusters for transporters and cytoplasmic enzymes, evolutionary innovation arises in a manner analogous to the evolution of proteins through new combinations of existing protein 
domains $(21,28)$. The lateral transfer of genetic modules encoding BMCs appears to be a frequent mechanism for adding to the core repertoire of bacterial genomes to expand the metabolic capacity of the recipient and enable adaptation to new ecological niches. As such, BMCs have tremendous potential for bioengineering of metabolic modules in bacteria; the first proof-of-concept for this approach was recently described by Parsons et al. (46).

Given the similarity in ultrastructure and in the underlying design principles in the architecture of their shells $(36,70,71)$, what is the relationship of the BMC shell to viral capsids? The structural similarity may simply reflect convergence, driven by the geometric constraints on a selforganizing protein shell (43). Divergence from a common ancestor is as yet unsupported; to date, there is no evidence for primary or tertiary structure similarity of the BMC shell proteins to any viral capsid proteins. This might be explained by the relative small number of viral capsid proteins that have had their sequence or fold characterized; alternatively, the shell proteins are similar to ancient viral capsid proteins no longer extant. In any case, if the BMC shell proteins do prove to be evolutionarily related to capsid proteins, what was the direction of the gene transfer? Were the BMC shell proteins acquired through a phage infection? If bacteriophages are derived from bacterial genomes, is the viral capsid derived from the BMC? Currently available data suggests that most horizontal gene transfer flows from cells to viruses (summarized in (43)); considering this, the BMC shell may have been co-opted by viruses for the encapsulation of nucleic acids.

\section{SUMMARY POINTS}

1. BMCs are functionally diverse metabolic modules in bacteria; they are defined by their proteinaceous shell and their enzyme contents. 
2. The genes for two shell protein families are found in all BMC gene clusters; the assemblies of these proteins (Pf00936 and Pf03319) are the common building blocks of BMC shells.

3. The genes encoding BMCs have been subjected to frequent horizontal gene transfer and are widespread among the bacterial phyla.

\section{FUTURE ISSUES}

1. The proposed functions and metabolic capabilities of the various BMCs require direct experimental evidence. Steps towards that goal include expression studies under relevant growth conditions, development of purification procedures that permit the establishment of complete inventories of their protein constituents, kinetic characterization of the encapsulated enzymes and reconstruction of the metabolic steps that take place in the $\mathrm{BMC}$ interior.

2. How do BMCs assemble? Of particular significance are the structural signatures on the encapsulated proteins that guide their incorporation into a $\mathrm{BMC}$ and mediate requisite interactions with other BMC components. Likewise, knowledge of strategies that ensure balanced expression of all BMC proteins, apparently of great importance for the assembly of BMCs of normal shape, is of importance.

3. How are the additional proteins known to be associated with the BMC shell integrated into or associated with the protein assemblies that form the shell facets and vertices?

4. How dynamic is the BMC shell? Do its composition and permeability properties change in response to environmental conditions and to changes in intracellular metabolite ratios? 
Do they self-repair? Does BMC size change to regulate its internal metabolism, in a manner analogous to the way the mitochondrion regulates the Krebs cycle with changes in size?

5. Little experimental evidence exists that addresses the flux of reactants into the BMC or the efflux of products out of the particles. Can mathematical models be developed that predict the flux across the shell and can serve as a guide for further biochemical experiments?

6. What signals trigger biogenesis of BMCs? The sensors, signaling cascade(s) and regulatory mechanisms on the transcriptional and translational levels are currently unknown for most BMCs, so is the question whether organisms are able to express more than one BMC type at a time.

7. What is the evolutionary relationship between the shells of BMCs and viral capsids?

\section{Acknowledgements}

We thank Jeffrey Blanchard and Todd Yeates for providing results prior to publication. We thank Seth Axen for help in figure preparation and Bill Greenleaf and Jay Kinney for helpful discussions. CAK, SH and GCC acknowledge support of the NSF (MCB 0851094 and MCB 0818680).

This work was also supported by the U.S. Department of Energy under Contract No. DE-AC02-05CH11231.

\section{LITERATURE CITED}

1. Badger MR, Bassett M, Comins HN. 1985. A model for $\mathrm{HCO}_{3}{ }^{-}$accumulation and photosynthesis in the cyanobacterium Synechococcus sp: Theoretical predictions and experimental observations. Plant Physiol. 77: 465-71 
2. Badger MR, Hanson D, Price GD. 2002. Evolution and diversity of $\mathrm{CO}_{2}$ concentrating mechanisms in cyanobacteria. Funct. Plant Biol. 29: 161-73

3. Badger MR, Price GD. 1992. The $\mathrm{CO}_{2}$ concentrating mechanism in cyanobacteria and microalgae. Physiol. Plant. 90: 529-36

4. Badger MR, Price GD. 2003. $\mathrm{CO}_{2}$ concentrating mechanisms in cyanobacteria: molecular components, their diversity and evolution. J. Exp. Bot. 54: 609-22

5. Badger MR, Price GD, Long BM, Woodger FJ. 2006. The environmental plasticity and ecological genomics of the cyanobacterial $\mathrm{CO}_{2}$ concentrating mechanism. J. Exp. Bot. 57: 249-65

6. Baker SH, Jin S, Aldrich HC, Howard GT, Shively JM. 1998. Insertion mutation of the form I $c b b L$ gene encoding ribulose bisphosphate carboxylase/oxygenase (RuBisCO) in Thiobacillus neapolitanus results in expression of form II RuBisCO, loss of carboxysomes, and an increased $\mathrm{CO}_{2}$ requirement for growth. J. Bacteriol. 180: 4133-9

7. Bobik TA, Havemann GD, Busch RJ, Williams DS, Aldrich HC. 1999. The propanediol utilization ( $p d u$ ) operon of Salmonella enterica serovar Typhimurium LT2 includes genes necessary for formation of polyhedral organelles involved in coenzyme B(12)-dependent 1, 2-propanediol degradation. J Bacteriol 181: 5967-75

8. Bock E, Duval D, Peters KR. 1974. Charakterisierung eines phagenahnlichen Partikels aus Zellen von Nitrobacter. I. Wirstpartikelbeziehung und Isolierung. Arch. Microbiol. 97: $115-27$

9. Brinsmade SR, Escalante-Semerena JC. 2004. The eutD Gene of Salmonella enterica Encodes a Protein with Phosphotransacetylase Enzyme Activity. J. Bacteriol. 186: 18902

10. Brinsmade SR, Paldon T, Escalante-Semerena JC. 2005. Minimal functions and physiological conditions required for growth of Salmonella enterica on ethanolamine in the absence of the metabolosome. J Bacteriol 187: 8039-46

11. Butland G, Peregrin-Alvarez JM, Li J, Yang W, Yang X, et al. 2005. Interaction network containing conserved and essential protein complexes in Escherichia coli. Nature 433: 531-7

12. Cai F, Menon BB, Cannon GC, Curry KJ, Shively JM, Heinhorst S. 2009. The Pentameric Vertex Proteins Are Necessary for the Icosahedral Carboxysome Shell to Function as a $\mathrm{CO}_{2}$ Leakage Barrier. PLoS ONE 4: e7521

13. Cannon GC, Bradburne CE, Aldrich HC, Baker SH, Heinhorst S, Shively JM. 2001. Microcompartments in prokaryotes: carboxysomes and related polyhedra. Appl Environ Microbiol 67: 5351-61

14. Cannon GC, English RS, Shively JM. 1991. In situ assay of ribulose-1,5-bisphosphate carboxylase/oxygenase in Thiobacillus neapolitanus. J Bacteriol 173: 1565-8

15. Cannon GC, Heinhorst S, Bradburne CE, Shively JM. 2002. Carboxysome genomics: a status report. Funct Plant Biol 29: 175-82

16. Cannon GC, Heinhorst S, Kerfeld CA. 2009. carboxysomal carbonic anhydrases: Structure and role in microbial $\mathrm{CO}_{2}$ fixation. Biochim Biophys Acta in press

17. Chen P, Andersson DI, Roth JR. 1994. The control region of the $p d u / c o b$ regulon in Salmonella typhimurium. J. Bacteriol. 176: 5474-82

18. Crowley CS, Sawaya MR, Bobik TA, Yeates TO. 2008. Structure of the PduU shell protein from the Pdu microcompartment of Salmonella. Structure 16: 1324-32

19. DeLano WL. 2002. Palo Alto, CA: DeLano Scientific 
20. Dobrinski KP, Longo DL, Scott KM. 2005. The carbon-concentrating mechanism of the hydrothermal vent chemolithoautotroph Thiomicrospira crunogena. J Bacteriol 187:

5761-6

21. Doolittle RF. 1995. The multiplicity of domains in proteins. Ann. Rev. Biochem. 64: 287314

22. Dou Z, Heinhorst S, Williams EB, Murin CD, Shively JM, Cannon GC. 2008. $\mathrm{CO}_{2}$ fixation kinetics of Halothiobacillus neapolitanus mutant carboxysomes lacking carbonic anhydrase suggest the shell acts as a diffusional barrier for $\mathrm{CO}_{2}$. J Biol Chem 283: 1037784

23. Drews G, Niklowitz W. 1956. Beiträge zur Cytologie der Blaualgen. Arch Microbiol 24: 147-62

24. English RS, Lorbach SC, Qin X, Shively JM. 1994. Isolation and characterization of a carboxysome shell gene from Thiobacillus neapolitanus. Mol Microbiol 12: 647-54

25. Faust LR, Connor JA, Roof DM, Hoch JA, Babior BM. 1990. Cloning, sequencing, and expression of the genes encoding the adenosylcobalamin-dependent ethanolamine ammonia-lyase of Salmonella typhimurium. Journal of Biological Chemistry 265: 124626

26. Fondi M, Emiliani G, Fani R. 2009. Origin and evolution of operons and metabolic pathways. Research in Microbiology 160: 502-12

27. Forouhar F, Kuzin A, Seetharaman J, Lee I, Zhou W, et al. 2007. Functional insights from structural genomics. J. Struct. Funct. Genomics 8: 37-44

28. Fraser HB. 2005. Modularity and evolutionary constraint on proteins. Nat Genet 37: 3512

29. Gitai Z. 2005. The New Bacterial Cell Biology: Moving Parts and Subcellular Architecture. Cell 120: 577-86

30. Havemann GD, Bobik TA. 2003. Protein content of polyhedral organelles involved in coenzyme B12-dependent degradation of 1,2-propanediol in Salmonella enterica serovar Typhimurium LT2. J Bacteriol 185: 5086-95

31. Havemann GD, Sampson EM, Bobik TA. 2002. PduA is a shell protein of polyhedral organelles involved in coenzyme B(12)-dependent degradation of 1,2-propanediol in Salmonella enterica serovar typhimurium LT2. J Bacteriol 184: 1253-61

32. Heinhorst S, Cannon GC, Shively JM. 2006. Carboxysomes and carboxysome-like inclusions. In Complex Intracellular Structures in Prokaryotes, ed. JM Shively, pp. 14164. Berlin/Heidelberg: Springer

33. Heldt D, Frank S, Seyedarabi A, Ladikis D, Parsons JB, et al. 2009. Structure of a trimeric bacterial microcompartment shell protein, EtuB, associated with ethanol utilization in Clostridium kluyveri. Biochemical Journal 423: 199-207

34. Jeter RM. 1990. Cobalamin-dependent 1,2-propanediol utilization by Salmonella typhimurium. J Gen Microbiol 136: 887-96

35. Kaplan A, Reinhold L. 1999. $\mathrm{CO}_{2}$ concentrating mechanisms in photosynthetic microorganisms. Annu Rev Plant Physiol Plant Mol Biol 50: 539-70

36. Kerfeld CA, Sawaya MR, Tanaka S, Nguyen CV, Phillips M, et al. 2005. Protein structures forming the shell of primitive bacterial organelles. Science 309: 936-8

37. Klein MG, Zwart P, Bagby SC, Cai F, Chisholm SW, et al. 2009. Identification and structural analysis of a novel carboxysome shell protein with implications for metabolite transport. J Mol Biol 392: 319-33 
38. Kofoid E, Rappleye C, Stojiljkovic I, Roth J. 1999. The 17-gene ethanolamine (eut) operon of Salmonella typhimurium encodes five homologues of carboxysome shell proteins. J Bacteriol 181: 5317-29

39. Lawrence JG, Roth JR. 1996. Selfish operons: Horizontal transfer may drive the evolution of gene clusters. Genetics 143: 1843-60

40. Leal N, Havemann G, Bobik T. 2003. PduP is a coenzyme-a-acylating propionaldehyde dehydrogenase associated with the polyhedral bodies involved in B 12-dependent 1,2propanediol degradation by Salmonella enterica serovar Typhimurium LT2. Archives of Microbiology 180: 353-61

41. Lurz R, Mayer F, Gottschalk G. 1979. Electron microscopic study on the quaternary structure of the isolated particulate alcohol-acetaldehyde dehydrogenase complex and its identity with the polygonal bodies of Clostridium kluveryi. Arch. Microbiol. 120: 255-62

42. Menon BB, Dou Z, Heinhorst S, Shively JM, Cannon GC. 2008. Halothiobacillus neapolitanus carboxysomes sequester heterologous and chimeric RubisCO species. PLoS ONE 3: e3570

43. Moreira D, Lopez-Garcia P. 2009. Ten reasons to exclude viruses from the tree of life. Nature Reviews Microbiology 7: 306-11

44. Mori K, Bando R, Hieda N, Toraya T. 2004. Identification of a Reactivating Factor for Adenosylcobalamin-Dependent Ethanolamine Ammonia Lyase. J. Bacteriol. 186: 684554

45. O'Brien JR, Raynaud C, Croux C, Girbal L, Soucaille P, Lanzilotta WN. 2004. Insight into the Mechanism of the B12-Independent Glycerol Dehydratase from Clostridium butyricum: Preliminary Biochemical and Structural Characterizationâ $€_{i}$. Biochemistry 43: $4635-45$

46. Parsons JB, Dinesh SD, Deery E, Leech HK, Brindley AA, et al. 2008. Biochemical and structural insights into bacterial organelle form and biogenesis. J Biol Chem 283: 1436675

47. Penrod JT, Roth JR. 2006. Conserving a volatile metabolite: a role for carboxysome-like organelles in Salmonella enterica. J Bacteriol 188: 2865-74

48. Price G, Howitt S, Harrison K, Badger M. 1993. Analysis of a genomic DNA region from the cyanobacterium Synechococcus sp. strain PCC7942 involved in carboxysome assembly and function. J. Bacteriol. 175: 2871-9

49. Price GD, Badger MR. 1989. Isolation and characterization of high $\mathrm{CO}_{2}$-requiringmutants of the cyanobacterium Synechococcus PCC 7942: Two phenotypes that accumulate inorganic carbon but are apparently unable to generate $\mathrm{CO}_{2}$ within the carboxysome. Plant Physiol. 91: 514-25

50. Price GD, Badger MR. 1991. Evidence for the role of carboxysomes in the cyanobacterial $\mathrm{CO}_{2}$-concentrating mechanism. Can J Bot 69: 963-73

51. Price GD, Badger MR, Woodger FJ, Long BM. 2008. Advances in understanding the cyanobacterial $\mathrm{CO}_{2}$-concentrating-mechanism $(\mathrm{CCM})$ : functional components, $\mathrm{Ci}$ transporters, diversity, genetic regulation and prospects for engineering into plants. $J$ Exp Bot 59: 1441-61

52. Raven JA, Lucas WJ. 1985. The energetics of carbon acquisition. In Inorganic Carbon Uptake by Aquatic Photosynthetic Organisms, ed. WJ Lucas, JA Berry, pp. 305-24. Rockville, MD: American Society of Plant Physiologists 
53. Raynaud Cl, SarÃßabal P, Meynial-Salles I, Croux C, Soucaille P. 2003. Molecular characterization of the 1,3-propanediol (1,3-PD) operon of Clostridium butyricum. Proceedings of the National Academy of Sciences of the United States of America 100: 5010-5

54. Reinhold L, Kosloff R, Kaplan A. 1991. A model for inorganic carbon fluxes and photosynthesis in cyanobacteria. Can J Bot 69: 984-8

55. Reinhold L, Zviman M, Kaplan A. 1987. Inorganic carbon fluxes and photosynthesis in cyanobacteria. A quantitative model. In Progress in Photosynthetic Research, ed. J Biggens, pp. 6.289-6.96. Dordrecht: Martinus Nijhoff

56. Reinhold L, Zviman M, Kaplan A. 1989. A quantitative model for carbon fluxes and photosynthesis in cyanobacteria. Plant Physiol Biochem 27: 945-54

57. Rondon M, Kazmierczak R, Escalante-Semerena J. 1995. Glutathione is required for maximal transcription of the cobalamin biosynthetic and 1,2-propanediol utilization $(\mathrm{cob} / \mathrm{pdu})$ regulon and for the catabolism of ethanolamine, 1,2-propanediol, and propionate in Salmonella typhimurium LT2. J. Bacteriol. 177: 5434-9

58. Sagermann M, Ohtaki A, Nikolakakis K. 2009. Crystal structure of the EutL shell protein of the ethanolamine ammonia lyase microcompartment. Proc Natl Acad Sci USA 106: $8883-7$

59. Seedorf H, Fricke WF, Veith B, Bruggemann H, Liesegang H, et al. 2008. The genome of Clostridium kluyveri, a strict anaerobe with unique metabolic features. Proc Natl Acad Sci USA 105: 2128-33

60. Sheppard DE, Penrod JT, Bobik T, Kofoid E, Roth JR. 2004. Evidence that a B12Adenosyl Transferase Is Encoded within the Ethanolamine Operon of Salmonella enterica. J. Bacteriol. 186: 7635-44

61. Shively JM, Ball F, Brown DH, Saunders RE. 1973. Functional organelles in prokaryotes: polyhedral inclusions (carboxysomes) of Thiobacillus neapolitanus. Science 182: $584-6$

62. Shively JM, Bradburne CE, Aldrich HC, Bobik TA, Mehlman JL, et al. 1998. Sequence homologs of the carboxysomal polypeptide CsoS1 of the thiobacilli are present in cyanobacteria and enteric bacteria that form carboxysomes-polyhedral bodies. Can J Bot 76: $906-16$

63. Sriramulu DD, Liang M, Hernandez-Romero D, Raux-Deery E, Lunsdorf H, et al. 2008. Lactobacillus reuteri DSM 20016 produces cobalamin-dependent diol dehydratase in metabolosomes and metabolizes 1,2-propanediol by disproportionation. J Bacteriol 190: 4559-67

64. Starai VJ, Garrity J, Escalante-Semerena JC. 2005. Acetate excretion during growth of Salmonella enterica on ethanolamine requires phosphotransacetylase (EutD) activity, and acetate recapture requires acetyl-CoA synthetase (Acs) and phosphotransacetylase (Pta) activities. Microbiology 151:3793-801

65. Stojiljkovic I, Baumler AJ, Heffron F. 1995. Ethanolamine utilization in Salmonella typhimurium: nucleotide sequence, protein expression, and mutational analysis of the cchA cchB eutE eutJ eut G eutH gene cluster. J Bacteriol 177: 1357-66

66. Sutter M, Boehringer D, Gutmann S, Gunther S, Prangishvili D, et al. 2008. Structural basis of enzyme encapsulation into a bacterial nanocompartment. Nat Struct Mol Biol 15: 939-47 
67. Tanaka S, Kerfeld CA, Sawaya MR, Cai F, Heinhorst S, et al. 2008. Atomic-level models of the bacterial carboxysome shell. Science 319: 1083-6

68. Tanaka S, Sawaya MR, Phillips M, Yeates TO. 2009. Insights from multiple structures of the shell proteins from the beta-carboxysome. Protein Science 18: 108-20

69. Tanaka S, Sawaya MR, Yeates TO. in press. Structure and mechanisms of a proteinbased organelle in E. coli. Science

70. Tsai Y, Sawaya MR, Cannon GC, Cai F, Williams EB, et al. 2007. Structural analysis of CsoS1A and the protein shell of the Halothiobacillus neapolitanus carboxysome. PLoS Biol 5: e144

71. Yeates TO, Kerfeld CA, Heinhorst S, Cannon GC, Shively JM. 2008. Protein-based organelles in bacteria: carboxysomes and related microcompartments. Nat Rev Micro 6: 681-91 


\section{Figure Legends}

1. Transmission electron micrographs of bacterial microcompartments. (a) The cyanobacterium Synechocystis PCC6803 with a single carboxysome (P. Shih and C.

Kerfeld, unpublished); (b) Pdu and (c) Eut BMCs in Salmonella (Courtesy of Jess

Shively and the late Henry Aldrich). (d) BMCs in Clostridium kluveryi grown on ethanol and acetate, courtesy of Dr. Rudi Lurz, Max Planck Institute for Molecular Genetics; (e) BMCs in Clostridium phytofermans grown on fucose, courtesy of Dr. Jeffrey Blanchard, University of Massachusetts; (f) Putative BMCs in Pirellula staleyii courtesy of Dr. Manfred Rohde, Helmholtz Centre for Infection Research.

2. Schematic representation of the function of the (a) carboxysome, (b) Pdu BMC (c) Eut BMC and $(d)$ Etu BMC. For the Etu BMCs, the locus tags of the aldehyde and alcohol dehydrogenases are given.

3. The elements of the architecture of the carboxysome, depicted as an icosahedron assembled from hexamers (single BMC domain proteins; shown in blue), pseudohexamers (tandem BMC domain proteins; shown in green, gold and pink) and pentamers (quaternary structure of Pf03319 domain in CcmL; shown in yellow). For each of the electrostatic surface renderings of representative BMC shell proteins, the concave face is shown uppermost, followed by the relatively convex face and then crosssectional view showing the (putative) pores. The EutS cross section is shown in two orientations to show the $\sim 40^{\circ}$ distortion in the hexamer. The CsoS1D pseudohexamer is shown in its open form; in the cross-section the tightly appressed pair of trimers is shown, 
one in the open and the other in the closed conformation. Figure prepared with Pymol (19) and Google Sketchup from PDB codes 3DNC (CcmK2), 3CGI (PduU), 3 I87 (EutS), 3F56 (CsoS1D), 3GFH (EutL) and 2QW7 (CcmL). Electrostatics were generated using the APBS plugin for Pymol. Surface potentials for electrostatics were visualized with a low value of -10 (red) and a high value of +10 (blue). 


\section{Sidebar}

To date, evidence for BMCs has not been found in the Archaea. However, new type of protein compartment found in both Archaea and the Bacteria was recently characterized from Thermotoga maritima (66). With a diameter of only 20-24 nm, this structure is considerably smaller than other BMCs. The shell of this nanocompartment is built from 12 homopentamers of the $31 \mathrm{kDa}$ protein encapsulin. The interior is occupied by either an iron dependent peroxidase or a protein related to the iron carrier ferritin. These proteins, which may play a role in protecting the bacteria from oxidative damage, are targeted to the inside of the encapsulin particle through their C-terminal region, which binds to specific sites on the encapsulin shell. (see sidebar figure)

\section{Acronyms}

BMC Bacterial microcompartment

CCM Carbon concentrating mechanism

DIC Dissolved inorganic carbon

Eut Ethanolamine utilization

Pdu Propanediol utilization

Etu Ethanol utilization

3-PGA 3-phosphoglycerate

RubisCO ribulose-1,5-bisphosphate carboxylase/oxygenase

RubP ribulose 1,5-bisphosphate

TEM transmission electron microscopy 


\section{Glossary}

Bacterial microcompartment (BMC) A general name for self-assembling polyhedral organelles composed entirely of protein.

Carboxysome The BMC of many autotrophic bacteria that enhances the catalytic performance of the encapsulated RubisCO and constitutes the final step of a $\mathrm{CO}_{2}$ concentrating mechanism.

Pf00936 domain The $\sim 80$ amino acid sequence known as the BMC domain that is the main building block of the bacterial microcompartment shell.

Pf03319 domain The $\sim 80$ amino acid domain observed to form pentamers, or hexamers. Pentameric forms are thought to occupy the vertices in icosahedral BMCs.

Icosahedral Symmetry An icosahedron is composed of 20 facets and 12 vertices. In BMCs, the facets are presumably built up from layers of BMC-domain proteins that form hexamers and pseudohexamers; the 12 pentameric 'defects' are thought to be composed of the Pf03319 domain protein assembled as pentamers.

her mutants Mutants of autotrophic bacteria that are impaired in efficient carbon assimilation and require elevated $\mathrm{CO}_{2}$ concentrations to support wild type growth rates. 
CCM A multi-component $\mathrm{CO}_{2}$ concentrating mechanism of cyanobacteria and many chemoautotrophs that compensates for low levels of available inorganic carbon and poor $\mathrm{CO}_{2}$ fixation kinetics. The central component of the $\mathrm{CCM}$ is the carboxysome, a $\mathrm{BMC}$ that co-sequesters RubisCO and carbonic anhydrase.

Pdu operon An inducible bacterial operon of 23 individual genes; its protein products mediate the utilization of 1,2-propanediol as a carbon and energy source in a Pdu BMC.

Eut operon An inducible bacterial operon of 17 individual genes; its protein products mediate the degradation of ethanolamine as a carbon and energy source in a Eut BMC.

Enterosome Previously coined term for Pdu and Eut BMCs of enteric bacteria.

Metabolosome Alternative term for BMCs.

Coenzyme $\mathbf{B}_{12}$ A complex organometallic cofactor associated with enzymes central to the degradation pathways of ethanolamine and 1,2-propandiol. 


\section{Reference Annotations}

Kerfeld CA, Sawaya MR, Tanaka S, Nguyen CV, Phillips M, et al. 2005. Protein structures forming the shell of primitive bacterial organelles. Science 309: 936-8

The first structural studies on the BMC shell that revealed the fold of the BMC domain and suggested that facets of the organelle were built as molecular layers of these proteins

Klein MG, Zwart P, Bagby SC, Cai F, Chisholm SW, et al. 2009. Identification and structural analysis of a novel carboxysome shell protein with implications for metabolite transport. $J$ Mol Biol 392:319-333.

The first report of the structure of a tandem-BMC domain protein, revealing pseudohexamers compatible with previous models for the BMC shell and the first observation of the potential for gating the pores in BMCs to regulate flux across the shell.

Lawrence JG, Roth JR. 1996. Selfish operons: Horizontal transfer may drive the evolution of gene clusters. Genetics 143: 1843-60.

The concept of selfish operons, suggesting that that horizontal transfer of compact groups of functionally related genes favors their retention, provides a parsimonious explanation for the widespread appearance of BMC gene clusters in diverse phyla.

Shively JM, Ball F, Brown DH, Saunders RE. 1973. Functional organelles in prokaryotes: polyhedral inclusions (carboxysomes) of Thiobacillus neapolitanus. Science 182: 584-6. First report that BMCs contain metabolically important enzymes and proposal of the name carboxysome for the BMCs of autotrophs. 
Havemann GD, Bobik TA. 2003. Protein content of polyhedral organelles involved in coenzyme B12-dependent degradation of 1,2-propanediol in Salmonella enterica serovar Typhimurium LT2. J Bacteriol 185: 5086-95. First molecular analysis of non-carboxysome BMCs and proposal of Pdu BMC function.

Shively JM, Bradburne CE, Aldrich HC, Bobik TA, Mehlman JL, et al. 1998. Sequence homologs of the carboxysomal polypeptide CsoS1 of the thiobacilli are present in cyanobacteria and enteric bacteria that form carboxysomes-polyhedral bodies. Can J Bot 76: 906-16. First evidence that carboxysome shell protein homologs form BMCs in heterotrophs.

Dou Z, Heinhorst S, Williams EB, Murin CD, Shively JM, Cannon GC. 2008. $\mathrm{CO}_{2}$ fixation kinetics of Halothiobacillus neapolitanus mutant carboxysomes lacking carbonic anhydrase suggest the shell acts as a diffusional barrier for $\mathrm{CO}_{2}$. J Biol Chem 283: 10377-84. First direct evidence that the shell of carboxysomes acts as a diffusional barrier for $\mathrm{CO}_{2}$.

Penrod JT, Roth JR. 2006. Conserving a volatile metabolite: a role for carboxysome-like organelles in Salmonella enterica. J Bacteriol 188: 2865-74. First to suggest a common functional paradigm for BMCs.

Brinsmade SR, Paldon T, Escalante-Semerena JC. 2005. Minimal functions and physiological conditions required for growth of Salmonella enterica on ethanolamine in the absence of the 
metabolosome. J Bacteriol 187: 8039-46. Demonstration that overexpression of BMC enzymes can overcome lack of the compartment itself.

Reinhold L, Zviman M, Kaplan A. 1987. Inorganic carbon fluxes and photosynthesis in cyanobacteria. A quantitative model. In Progress in Photosynthetic Research, ed. J Biggens, pp. 6.289-6.96. Dordrecht: Martinus Nijhoff. First quantitative model of CCM function in cyanobacteria.

Price GD, Badger MR. 1991. Evidence for the role of carboxysomes in the cyanobacterial $\mathrm{CO}_{2-}$ concentrating mechanism. Can J Bot 69: 963-73. First direct evidence that carboxysomes are a necessary component of the CCM in cyanobacteria. 
TABLE 1 Examples of BMC gene clusters in bacterial genomes of diverse phyla ${ }^{\mathrm{a}}$

\begin{tabular}{|c|c|c|}
\hline Representative organisms & Phyla & $\begin{array}{l}\text { Putative key associated enzymes } \\
\text { based on annotation }\end{array}$ \\
\hline Sebaldella termitidis & Fusobacteria & Fusion of pdu and eut operons \\
\hline $\begin{array}{l}\text { Thermanaerovibrio acidaminovorans DSM } \\
6589 \\
\text { Dethiosulfovibrio peptidovorans DSM11002 }\end{array}$ & Synergistetes & Eut and Pdu variants \\
\hline Clostridium phytofermans ISDg ${ }^{\mathrm{c}}$ & Firmicutes & $\begin{array}{l}\text { B12-indep. diol dehydratase } \\
\text { Fuculose 1-phosphate aldolase }\end{array}$ \\
\hline $\begin{array}{l}\text { Clostridium kluveryi DSM555 } \\
\text { (Etu BMC) }^{\mathrm{d}}\end{array}$ & Firmicutes & $\begin{array}{l}\text { Aldehyde dehydrogenase/Alcohol } \\
\text { dehydrogenase }\end{array}$ \\
\hline $\begin{array}{l}\text { Rhodopseudomonas palustris BisB18 } \\
\text { Ruminococcus obeum ATCC29174 } \\
\text { Clostridium novyi NT-2 } \\
\text { E. coli CFT073 } \\
\text { Shewanella putrefaciens CN-32 } \\
\text { E. coli } 536 \\
\text { Desulfotalea psychrophila } \text { LSv54 } \\
\text { Desulfovibiro desulfuricans G20 Vibrio } \\
\text { furnissii M1 }\end{array}$ & $\begin{array}{l}\text { Alphaproteobacteria } \\
\text { Firmicutes } \\
\text { Gammaproteobacteria } \\
\text { Deltaproteobacteria }\end{array}$ & $\begin{array}{l}\text { Glycyl radical enzyme with } \\
\text { homology to B12-independent diol } \\
\text { dehydratase }\end{array}$ \\
\hline $\begin{array}{l}\text { Pirellula staleyi DSM } 6068^{\mathrm{e}} \\
\text { Opitutus terrae PB90-1 }\end{array}$ & $\begin{array}{l}\text { Planctomycetes } \\
\text { Verrucomicrobia }\end{array}$ & $\begin{array}{l}\text { Aldolase(s), } \\
\text { Lactate dehydrogenase } \\
\text { Acetate kinase }\end{array}$ \\
\hline $\begin{array}{l}\text { Mycobacterium smegmatis MC2 } 155 \\
\text { Rhodococcus RHA-1 (plasmid) } \\
\text { Verminephrobacter eiseniae EF01-2 }\end{array}$ & $\begin{array}{l}\text { Actinobacteria } \\
\text { Betaproteobacteria }\end{array}$ & $\begin{array}{l}\text { Aldehyde dehydrogenase; } \\
\text { Aminotransferase type III }\end{array}$ \\
\hline $\begin{array}{l}\text { Alkaliphilus metalliredigens QYMF } \\
\text { Carboxydothermus hydrogenoformans Z- } \\
2901\end{array}$ & Firmicutes & $\begin{array}{l}\text { Embedded in a cluster of genes } \\
\text { presumed to be involved in purine } \\
\text { metabolism }\end{array}$ \\
\hline $\begin{array}{l}\text { Methylibium petroleiphilum PM1 (plasmid) } \\
\text { Nakamurella multipartite }\end{array}$ & $\begin{array}{l}\text { Betaproteobacteria } \\
\text { Actinobcateria }\end{array}$ & $\begin{array}{l}\text { Malate/Lactate dehydrogenase-like } \\
\text { PduP/EutE Aldehyde } \\
\text { dehydrogenase; Glutathione } \\
\text { dependent formaldehyde } \\
\text { dehydrogenase }\end{array}$ \\
\hline Haliangium ochraceum SMP-2 & Deltaproteobacteria & Aldehyde dehydrogenase, Aldolase \\
\hline Chloroherpeton thalassium ATCC 35110 & Chlorobi & - \\
\hline Solibacter usitatus Ellin 6076 & Acidobacteria & $\begin{array}{l}\text { Aldehyde dehydrogenase, Aldolase, } \\
\text { dihydrodipicolinate synthetase }\end{array}$ \\
\hline \multicolumn{3}{|c|}{ a The representative organisms do not constitute a complete list of all observations } \\
\hline \multicolumn{3}{|c|}{${ }^{\text {b} A d a p t e d ~ f r o m ~ I n t e g r a t e d ~ M i c r o b i a l ~ G e n o m e s, ~ h t t p: / / i m g . j g i . d o e . g o v / c g i-b i n / p u b / m a i n . c g i ~}$} \\
\hline \multicolumn{3}{|l|}{ 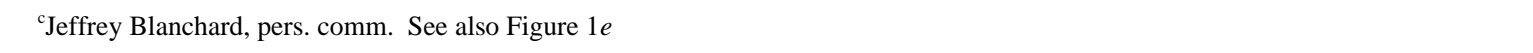 } \\
\hline dSee Figures $1 d, 2 d$ and references 33 and 59. & & \\
\hline
\end{tabular}



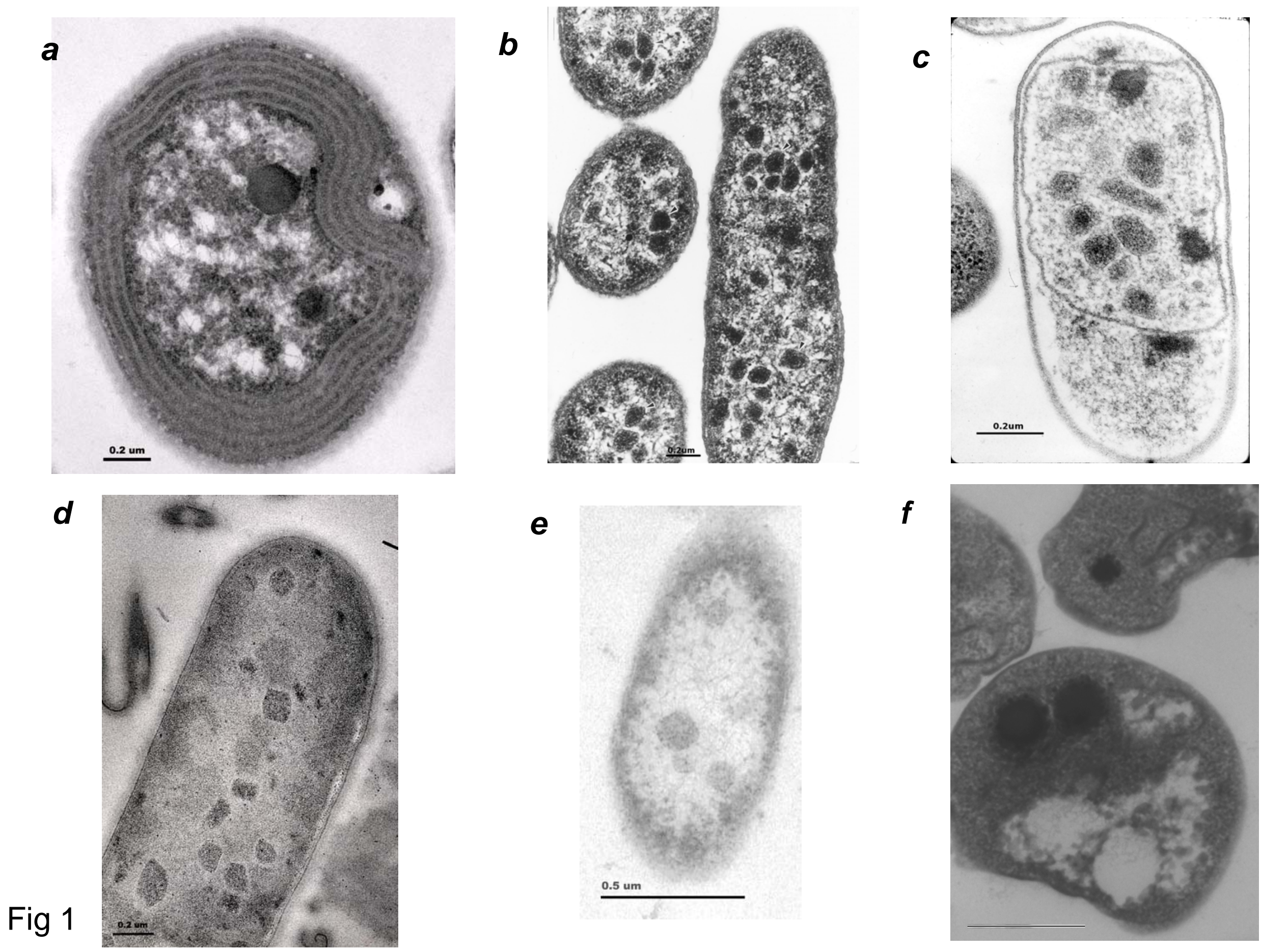
A

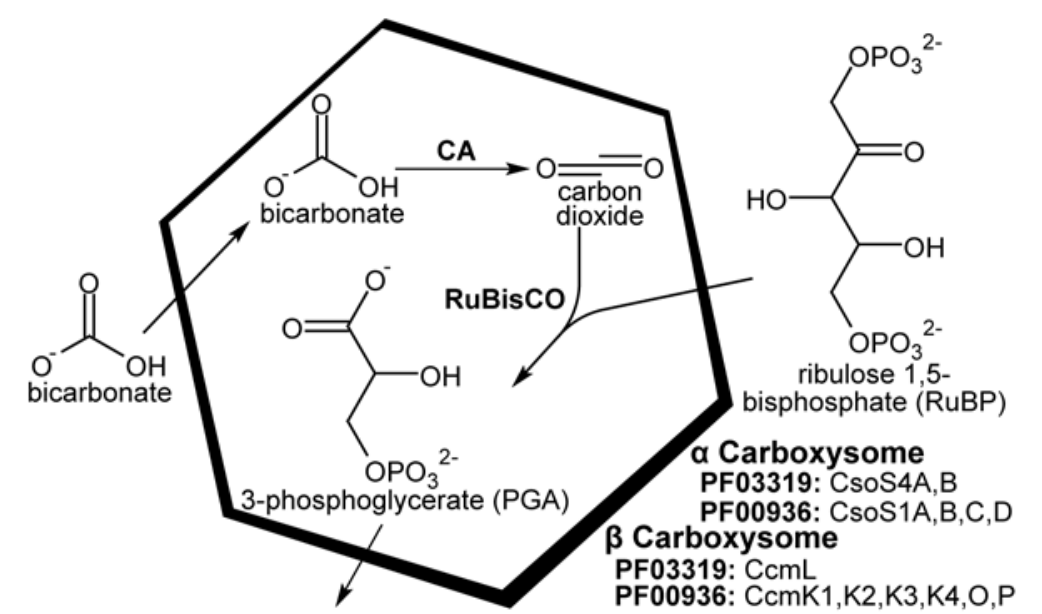

C

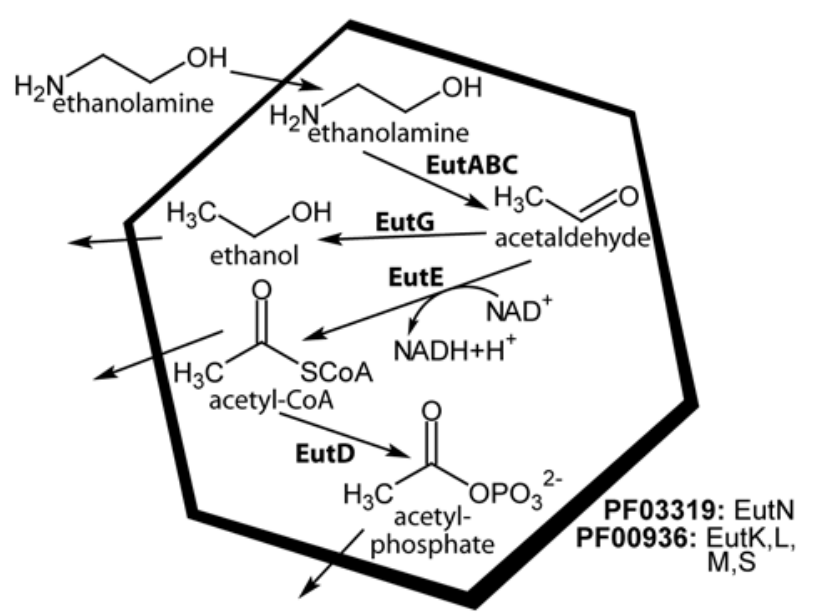

B

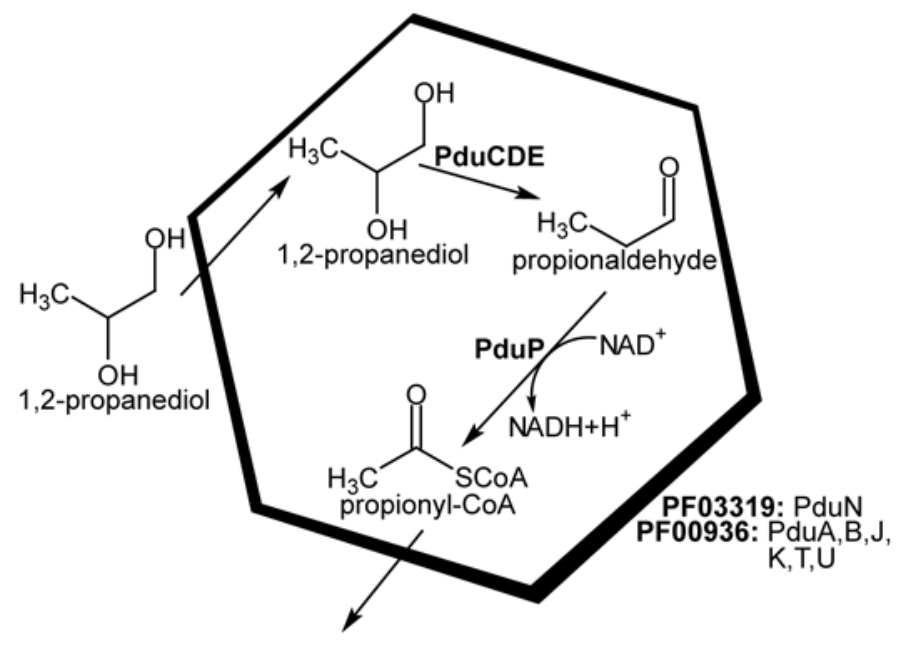

D

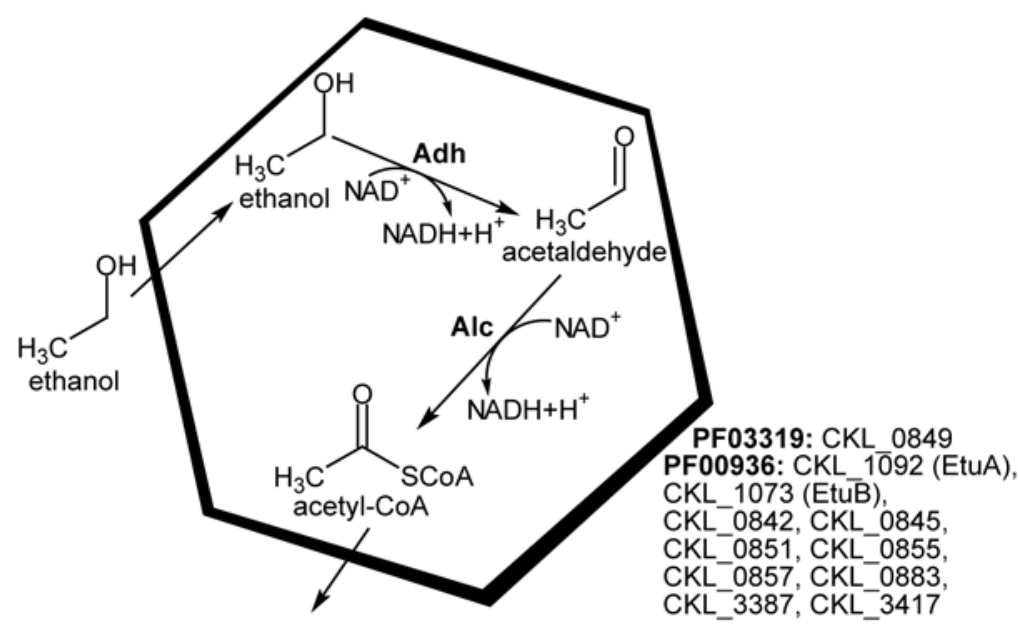

Fig 2 

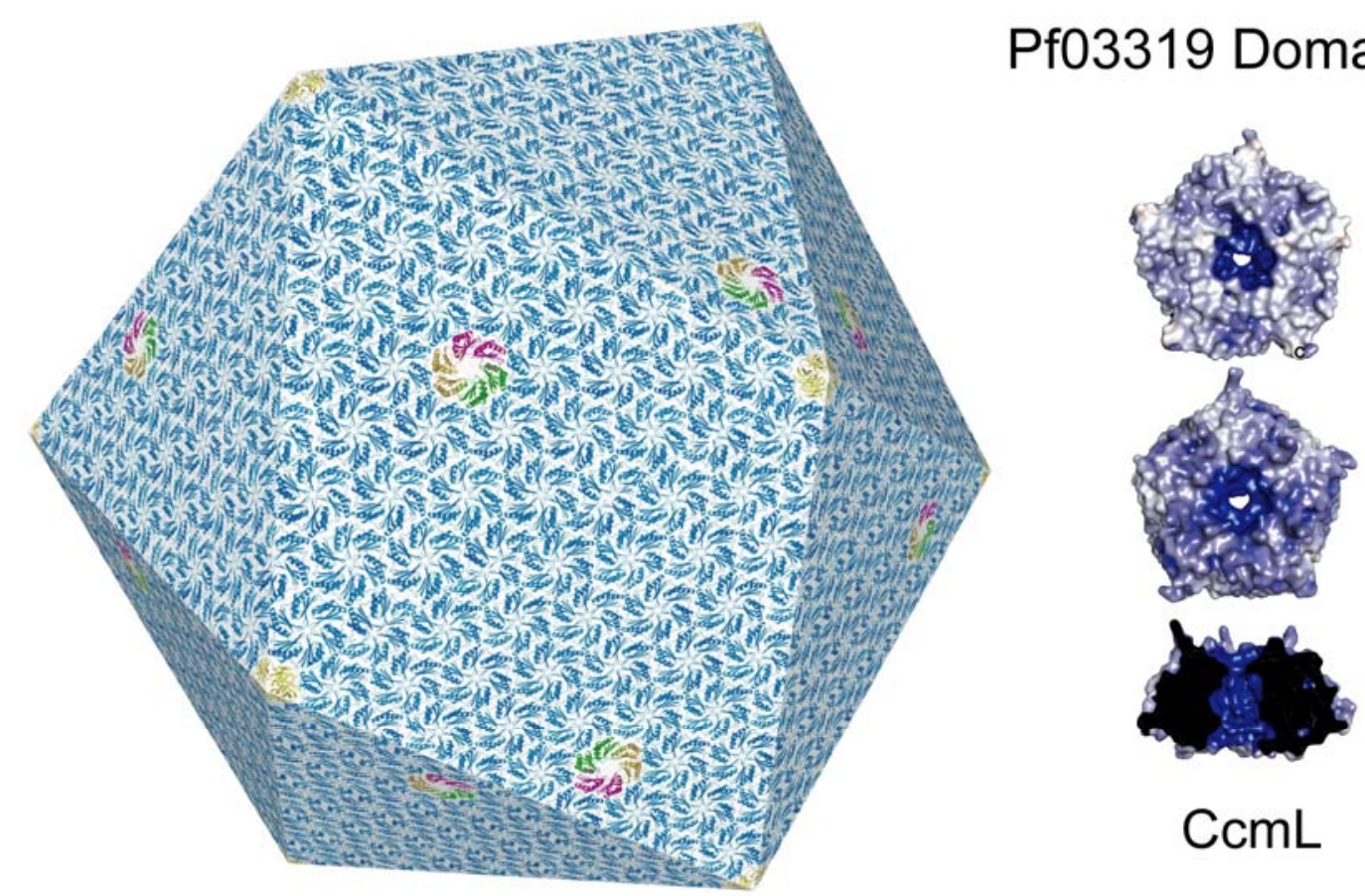

Single BMC Domain

Tandem BMC Domain

Fig 3
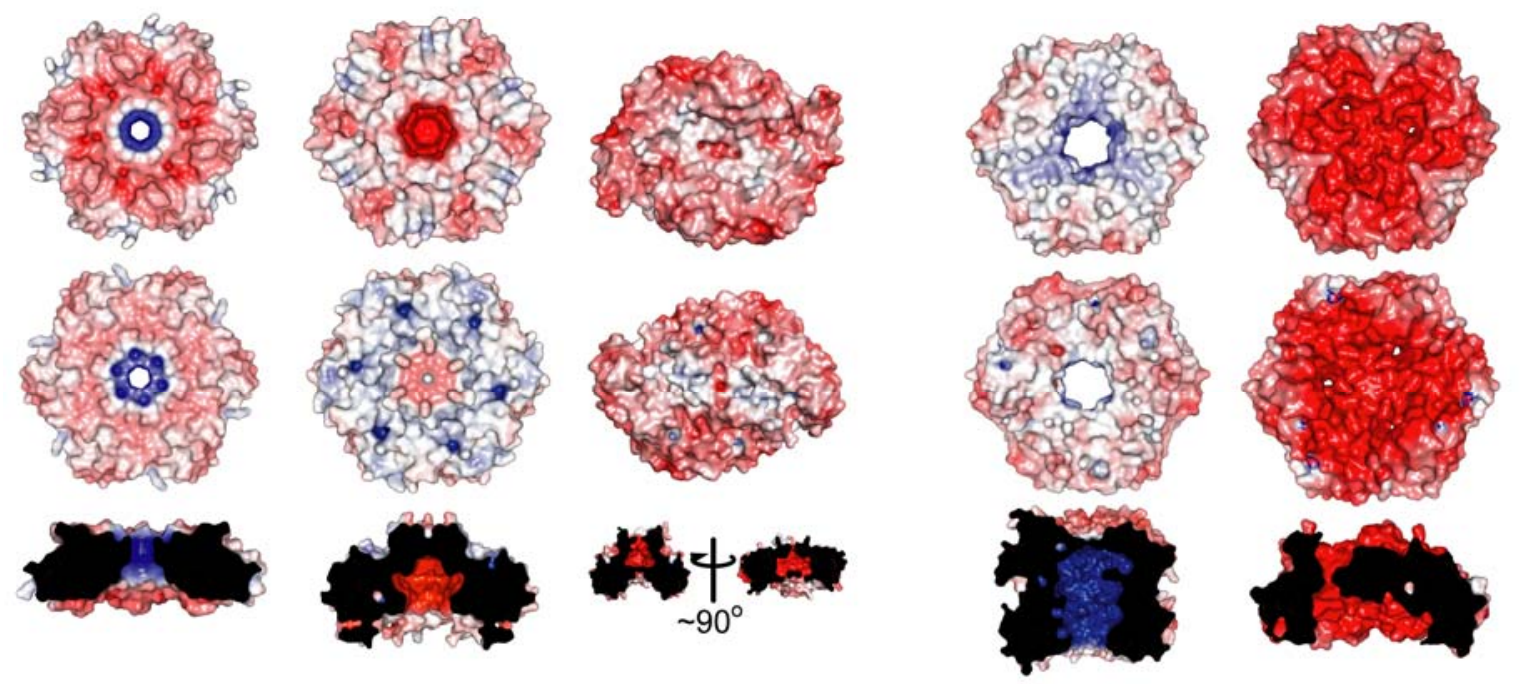

CcmK2

PduU

EutS

CsoS1D EutL 


\section{Sidebar Fig}

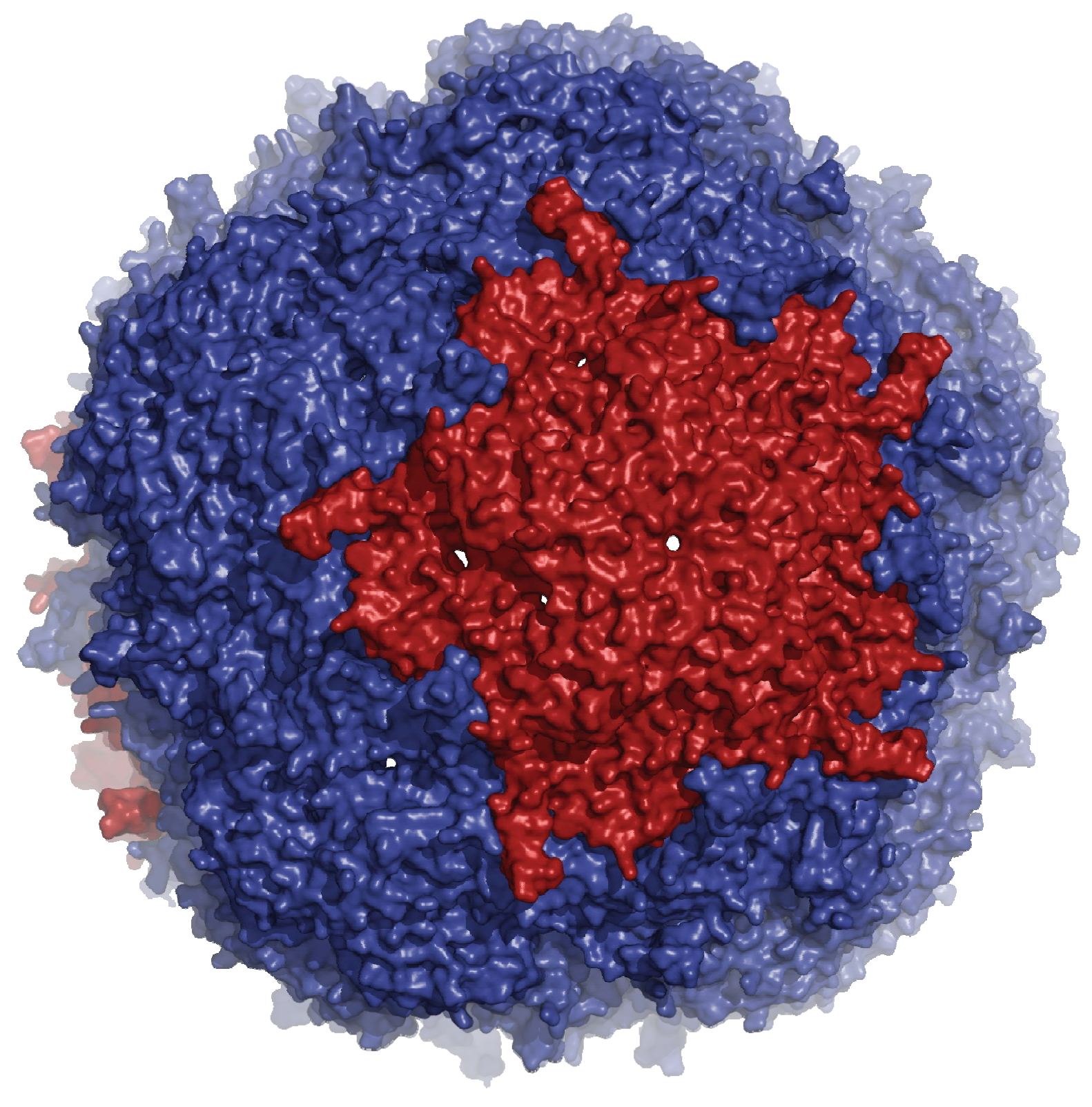

